\title{
FINANCIAMENTO DOS DIREITOS SOCIAIS NA CONSTITUIÇÃO DE 1988: DO "PACTO ASSIMÉTRICO" AO “ESTADO DE SÍTIO FISCAL”
}

\author{
Élida Graziane Pinto 10 \\ Salomáo Barros Ximenes ${ }^{2}$ (D
}

\begin{abstract}
Resumo: $\mathrm{O}$ trabalho analisa os princípios jurídico-políticos de proteção aos direitos sociais na Constituição de 1988 e as regras que instituíram garantias de financiamento adequado, proporcional e progressivo, com ênfase em saúde e educação. Essas regras criam um microssistema normativo que atribui sentido a determinadas fontes de receitas e vincula patamares de gasto mínimo a direitos definidos como prioridades orçamentárias. Discutimos a evolução desse sistema no período de 1988 a 2018, culminando com a Emenda no 95/2016, que fixou o Novo Regime Fiscal, medida equivalente a um "estado de sítio fiscal". Ao fim, discutimos alternativas de reequilíbrio intertemporal nas contas públicas que viriam em reforço ao sistema constitucional de promoção dos referidos direitos.
\end{abstract}

Palavras-chave: Direitos sociais. Financiamento da educação. Financiamento da saúde. Orçamento público. Novo Regime Fiscal.

\section{FinANCING OF SOCIAL RIGHTS IN THE 1988 CoNSTITUTION: THE "ASYMMETRICAL PACT" TO "FISCAL STATE OF SIEGE"}

ABSTRACT: This essay analyzes the legal-political principles of social rights' protection in the 1988 Constitution and the rules that established adequate, proportional and progressive funding guarantees, with emphasis on health and education. The integrated reading of such rules allows to infer that these rules create a normative micro-system that assigns meaning to certain sources of income and links levels of minimum spending to rights defined as allocative priorities. We discuss the evolution of this system in the period from 1988 to 2018, culminating with Amendment n. 95/2016, which established the "New Fiscal Regime", equivalent to a "Fiscal State". In the end, we discussed alternatives for intertemporal rebalancing in public accounts that, in the opposite direction, would reinforce the constitutional system to promote these fundamental rights.

Keywords: Social rights. Financing of education. Health financing. Public budget. New tax regime.

\footnotetext{
${ }^{1}$ Ministério Público de Contas do Estado de São Paulo - São Paulo (SP), Brasil. E-mail: egraziane@tce.sp.gov.br ${ }^{2}$ Universidade Federal do ABC, Centro de Engenharia, Modelagem e Ciências Sociais Aplicadas São Bernardo do Campo (SP), Brasil. E-mail: salomao.ximenes@ufabc.edu.br DOI: 10.1590/ES0101-73302018209544
} 


\title{
FINANCEMENT DES DROITS SOCIAUX DANS LA CONSTITUTION DE 1988 : DU « PACTE ASYMÉTRIQUE » AU « SIÈGE FISCAL »
}

\begin{abstract}
RÉSUMÉ: L'essai analyse les principes juridiques et politiques de la protection des droits sociaux dans la Constitution de 1988 et les règles qui établissent les garanties de financement adéquates, proportionnelles et progressives, en mettant l'accent sur la santé et l'éducation. La lecture intégrée de ces règles permet de déduire que ces règles créent un microsystème normatif qui attribue un sens à certaines sources de revenus et relie les niveaux de dépenses minimum aux droits définis comme priorités d'allocation du budget du cycle budgétaire. L'évolution de ce système dans la période de 1988 à 2018 est discuté, en aboutissant à l'amendement n. 95/2016, où s'est établi le "nouveau régime fiscal ", dont la répercussion pour les liens budgétaires soutiennent l'évaluation des coûts des droits sociaux comme équivalent à un "État fiscal ». En fin de compte, ce texte comporte des alternatives pour le rééquilibrage intertemporel dans les comptes publics qui, dans le sens inverse, renforceraient le système constitutionnel pour promouvoir ces droits fondamentaux.
\end{abstract}

Mots-clés : Droits sociaux. Financement de l'éducation. Financement de la santé. Budget public. Nouveau régime fiscal.

\section{Introdução}

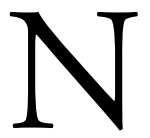

o Livro XII de Odisseia, o herói Ulisses ordena aos seus comandados que tapem os ouvidos com cera e o acorrentem firmemente ao mastro da embarcação, como preparativos para aproximação e passagem pelas proximidades da mítica ilha habitada pelas sereias (HOMERO, 2009). O canto delas, de táo sedutor, levaria os experientes guerreiros a desviarem a rota e se lançarem contra os rochedos, naufragando e, assim, abandonando por um arroubo o propósito maior de retorno à terra natal.

A Ulisses, amarrado, caberia ouvir os cantos e relatar esse conhecimento aos seus companheiros. "Encantado, acenei que me soltassem; Mas curvam-se remando, e com mais cordas Perimedes e Euríloco me arrocham" (HOMERO, 2009 , s. p.). Superada essa etapa da viagem, ele conclui: "Provado, amigos, temos outros males" (HOMERO, 2009, s. p.).

De modo análogo, constituições são correntes que deveriam dificultar ou mesmo impedir que uma determinada comunidade política, em momentos de crise ou comoção, viesse a abandonar seus propósitos igualitários mais elevados e de longo prazo (ELSTER, 2009) em favor de deman- 
das resultantes não das maiorias sociais, mas da captura da agenda política e econômica por interesses alheios às respectivas constituições. Estas são também documentos limitadores ou impeditivos de violação aos direitos das minorias políticas e sociais, mesmo quando uma maioria, por qualquer que seja o motivo, decida fazê-lo. Nesse duplo sentido — defesa dos propósitos igualitários e proteção aos direitos fundamentais das minorias —, não é demasiado recuperar a fronteira de contenção que as cláusulas pétreas encerram, na medida em que "As estratégias de pré-compromisso constitucionais poderiam servir para superar a miopia ou a fraqueza da vontade da coletividade" (SUNSTEIN, 1991, p. 641).

$\mathrm{Na}$ ocasião em que analisamos o legado e discutimos os desafios que decorrem das três décadas de vigência da Constituição Federal de 1988 (CF88), comemorada em um contexto de graves retrocessos jurídico-políticos que ameaçam frontalmente a realização dos objetivos constitucionais, parecenos necessário rememorar e analisar o essencial de nosso "pacto" constitucional de 1988.

Não será exagero retomar o significado jurídico-político da Constituição, seus princípios orientadores e, mais detidamente, a arquitetura de financiamento que ancora o microssistema de proteção orgânica e de tutela do custeio dos direitos sociais (PINTO, 2016b), que caracteriza o texto de 1988. Esse microssistema é a ferramenta jurídica básica, cujo aprimoramento viabilizaria o exercício progressivo dos direitos sociais que são requisitos democráticos essenciais. Retomando a analogia literária, é o mastro ao qual deveríamos estar aferrados em tempos de tormentas políticas e de míopes pressóes econômicas sobre o orçamento do Estado. Nessa altura dos acontecimentos, contudo, já está evidente o propósito de quebrar o mastro e romper o "pacto" de 1988, conforme analisaremos.

No artigo, portanto, discutiremos a estrutura e os princípios orientadores de proteção aos direitos sociais no Brasil, com ênfase nas vinculaçôes orçamentárias que amparam os direitos à educação e à saúde. Nesse ponto, apresentaremos a identidade e singularidade da CF88, uma Constituição que, pioneiramente, dedicou a mesma força protetiva ao conjunto dos direitos fundamentais - direitos civis e políticos e direitos econômicos, sociais e culturais (DESC) — , protegendo seus conteúdos e respectivas garantias em cláusulas pétreas (CF 88, art. 60, $\$ 4^{\circ}$, IV) que deveriam impedir reformas tendentes a aboli-los.

Ao declarar a aplicabilidade imediata desse conjunto de direitos e garantias e ao integrar o sistema constitucional brasileiro aos tratados internacionais de direitos humanos $\left(\mathrm{CF} / 88\right.$, art. $5^{\circ}, \$ \$ 1^{\circ}$ a $\left.3^{\circ}\right)$, por sua vez, a Constituição incorporou os princípios de exigibilidade jurídica (justiciabilidade), de máxima realização progressiva e de proibição do retrocesso (GOTTI, 2012; 
XIMENES, 2014; PINTO et al.; 2017). Formaliza, assim, como resultado das mobilizaçôes por justiça social e democracia, um verdadeiro "pacto assimétrico" (VIEIRA, 2013, p. 19), que garantiu relativa estabilidade institucional e normativa, a despeito de idas e vindas, ao menos até a crise político-constitucional do período recente.

Com isso, explicitamos o sentido constitucional das principais garantias constitucionais de financiamento aos direitos sociais, sua trajetória de avanços e retrocessos nos 30 anos de CF88, como pressupostos para um breve balanço das reformas constitucionais do período, até a promulgação da Emenda Constitucional no 95, de 2016 (EC 95), que institui - no âmbito do Ato das Disposiçóes Constitucionais Transitórias (ADCT) - o denominado Novo Regime Fiscal. Como medida extrema de ajuste fiscal, a iniciativa somente se justifica como norma impeditiva da progressividade de custeio para os pisos orçamentários da saúde e da educação, na medida em que quebra a sua relação de proporcionalidade com o comportamento da receita estatal, uma vez que assegura tão somente a correção monetária a partir do ano-base de 2017 até 2036, conforme demonstraremos.

No contexto de balanço de 30 anos da CF88, nosso ensaio tem o propósito de questionar a tese de inevitabilidade e univocidade do ajuste fiscal empreendido no bojo da EC95, razão pela qual busca oferecer algumas sugestóes alternativas de reequilíbrio mais equitativo nas contas públicas. Desse modo, refutamos as concepçóes elitistas e autoritárias que buscam subordinar a democracia e o direito constitucional à contenção linear das despesas primárias para forçar a reduçáo do tamanho do Estado e, com isso, preservar os interesses da pequena minoria rica e privilegiada que detém os capitais econômico e comunicacional e a hegemonia política.

Não nos limitaremos à compreensão, à crítica e à proposição, contudo. Isso porque também é preciso marcar o esforço de celebraçáo do "Espírito de 1988" - parafraseando o O Espirito de 45, filme-documentário de Loach (2013) sobre os compromissos políticos e civilizatórios que fundaram o Estado social inglês. O aprimoramento do pacto de 1988, em nosso caso, envolve a preservaçáo de seus objetivos, seus direitos e suas garantias fundamentais, reconhecendo que, dentro de seus marcos jurídicos, há muito a ser implementado, aprimorado e materializado em políticas econômicas, fiscais e sociais.

\section{Estado de direito democrático e social na Constituição de 1988: o pacto assimétrico}

A Constituição de 1988 declara que o Brasil é um Estado Democrático de Direito que tem entre os seus fundamentos "os valores sociais do 
trabalho e da livre iniciativa" e entre seus objetivos "erradicar a pobreza e a marginalização e reduzir as desigualdades sociais e regionais; promover o bem de todos, sem preconceitos de origem, raça, sexo, cor, idade e quaisquer outras formas de discriminação" (art. $1^{\circ}$, IV; art. $3^{\circ}$, III e IV, respectivamente), entre outros preceitos fundamentais. Arrola, em seguida, um extenso e aberto conjunto de direitos e deveres individuais e coletivos, com destaque para os direitos sociais (art. $5^{\circ}$ e seguintes). Ao tratar dos princípios gerais da ordem econômica, a CF88 diz que esta tem como finalidade "assegurar a todos existência digna, conforme os ditames da justiça social” (art. 170, caput), pondo lado a lado princípios como propriedade privada, funçáo social da propriedade, livre iniciativa e busca pelo pleno emprego (art. 170, II, III, IV e VIII, respectivamente). Esse, em termos gerais, é um dos arranjos jurídico-constitucionais típicos do que se convencionou genericamente denominar Estado social (SOTELO, 2010) ou, na tipologia de Habermas (2012), Estado de direito democrático e social.

O Estado de direito democrático e social, nesse sentido, é o tipo histórico de Estado característico do século XX, resultado das inflexões institucionais provocadas pelo ascenso da organização e da luta dos trabalhadores. São marcos nesse processo as Constituiçóes Mexicana de 1917 e Alemã de 1919 (Constituição de Weimar). Cury (1998), nesse debate, analisa a importância de Weimar para o desenho de proteção constitucional do direito à educação no Brasil, com influência direta na Constituição de 1934 e, indireta, na de 1988.

Para Habermas (2012), trata-se do quarto impulso de juridificação no Estado moderno, com a

constitucionalização de uma relação de poder social ancorada em estruturas de classe. [...] Nesses casos, trata-se de processos de juridificação num mundo do trabalho inicialmente sujeito ao poder de disposição ilimitado e ao poder de organização dos meios de produção dos proprietários privados (HABERMAS, 2012, p. 649).

A ideia de constitucionalização da relação capital-trabalho significa tanto impor limites jurídicos à contratualização entre os agentes econômicos privados como dispor de instrumentos de proteção social, a chamada seguridade social - previdência, assistência e saúde - e de "salário indireto" via garantia de escolas, transporte, cultura e lazer, etc. O Estado deve operar algum nível de redistribuiçẫo da mais-valia, viabilizando, assim, o difícil equilíbrio entre democracia de massas e acumulação capitalista por intermédio de "um arranjo domesticador do antagonismo de classes presente no sistema econômico" (HABERMAS, 2012, p. 631). Equilíbrio cuja sustentação depende da continuidade do crescimento capitalista, da coordenação de expectativas e 
da manutenção dos rituais de distribuição de benefícios sociais juridicamente regulados. Para isso, o Estado social incorpora uma retórica de progresso distributivo, capaz de estabelecer acordos de longo prazo entre capital e trabalho (SOTELO, 2010). Esses compromissos são comumente expressos em normas jurídicas e planos de desenvolvimento, por esse motivo, contextos de crise econômica são especialmente determinantes ao desequilibrar o arranjo domesticador e, com isso, colocar em questão o modelo de Estado social e a proteçáo aos direitos sociais (OSKOZ, 2013).

A CF88 é reconhecidamente fruto do embate de uma pluralidade de projetos e interesses que convergiram - tanto quanto possível - para o processo constituinte na redemocratização da década de 1980. Naquele contexto, nenhum dos polos chegou a lograr uma posiçáo hegemônica no processo e, como consequência, no texto da Constituição. Inegavelmente, contudo, os diferentes movimentos sociais organizados em torno do debate constituinte levaram ao texto de 1988 um conjunto de demandas populares de caráter reformista, como a universalização da seguridade social, o Sistema Único de Saúde (SUS) e o direito à creche e à pré-escola, entre outros.

O "arranjo domesticador de antagonismos" referido por Habermas (2012, p. 495) é, dessa maneira, em nosso contexto, reafirmado e requalificado:

A Constituição de 1988 não foi um pacto social entre iguais, mas também não pode ser confundida com uma simples carta de fachada ou simbólica, voltada a encobrir um rústico modelo de dominação. Temos um pacto assimétrico (VIEIRA, 2013, p. 19).

Feito esse enquadramento geral, variados são os modelos de juridificação e, consequentemente, de constitucionalização dos elementos básicos do Estado social e de sua política social (ESPING-ANDERSEN, 1991). A própria constitucionalização dos direitos sociais também se dá conforme diferentes modelos, dadas as características institucionais específicas de cada país, a path dependence, a interpretação dos Tribunais e o grau de mobilização dos trabalhadores. Analisaremos a Constituição de 1988 conforme algumas dessas características.

\section{As características essenciais da proteção aos direitos sociais na Constituição de 1988}

A primeira característica decorre do grau de reconhecimento das dimensöes objetiva e subjetiva dos direitos econômicos, sociais e culturais ${ }^{1}$. No início do atual impulso de juridificação, esses direitos foram incorporados às constituiçóes 
em sua dimensão objetiva, ou seja, enquanto deveres direcionados ao Estado e, sendo o caso, distribuídos aos entes subnacionais conforme o arranjo federativo nacional. Esse é o modelo típico da Constituição de Weimar (1919), já referida. Só na segunda metade do século XX, o novo constitucionalismo produzido nos países que superaram regimes ditatoriais levou ao reconhecimento da dimensão subjetiva dos direitos sociais, sendo típicas desse estágio a Constituição Portuguesa, de 1976 (CANOTILHO, 1999), além das do Brasil, 1988, e da África do Sul, de 1996 (NOVAIS, 2010). formas básicas:

Canotilho (1999) explica que a dimensão objetiva pode assumir duas

- $\quad$ a determinação de atuação positiva dos poderes para a criação do marco legal e institucional, ou seja, das condiçôes materiais para o exercício desses direitos;

- $\quad$ a oferta de políticas sociais e econômicas à população.

Em suma, a dimensão objetiva se caracteriza por vincular o Estado por meio da "fundamentação de deveres que não estão em relação com qualquer titular concreto" (CANOTILHO, 1999, p. 1.122). O direito subjetivo, por sua vez,

Trata-se de uma capacidade reconhecida ao indivíduo em decorrência de sua posição especial como membro da comunidade, que se materializa no poder de colocar em movimento normas jurídicas no interesse individual. (DUARTE, 2004, p. 113).

As vinculações orçamentárias nas áreas de política social, nesse sentido, são normas de direito objetivo cuja suspensão temporária na EC95, ainda que aplicada no orçamento, não afasta a dimensão subjetiva dos direitos em questão. Por isso, a eventual omissão no controle de constitucionalidade da EC95 pode vir a acentuar ainda mais a judicialização fragmentada destes.

Outra característica marcante entre os regimes constitucionais decorre da forma de incorporação de cláusulas superconstitucionais (VIEIRA, 1999), ou seja, normas constitucionais rígidas que traduzem limites materiais à erosão constitucional, associadas a mecanismos de controle de constitucionalidade de leis e de emendas à própria Constituição. Tais normas são as amarras de contenção cujo objetivo é preservar o pacto constitucional (assimétrico). "Esse movimento origina o denominado constitucionalismo democrático, [no qual] a preocupação não é tanto a extensão de direitos, mas o estabelecimento de limites à sua restrição" (XIMENES, 2014, p. 41). 
$\mathrm{Na}$ perspectiva jurídico-constitucional, há o que Ferrajoli (2001, p. 35-36) caracteriza como a dimensão substancial da democracia, em oposição à ideia de democracia formal. Nessa construção, os direitos fundamentais devem ser preservados e protegidos da esfera de deliberação de maiorias políticas e do livre mercado.

Nas constituiçōes em que as "cláusulas superconstitucionais" são estendidas à proteção dos direitos sociais, como é o caso da CF88, tais direitos e as demais regras constitucionais que viabilizam sua realização - as chamadas garantias constitucionais - devem limitar a discricionariedade de legisladores, juízes e administradores. De forma combinada, a Constituição visa retirar do espaço de deliberação a opção de não implementar os direitos e as garantias sociais nela reconhecidos - vedação à proteção insuficiente dos direitos ao mesmo tempo que objetiva tornar "indecidível que" (FERRAJOLI, 2001, p. 35) tais direitos e garantias sejam suprimidos ou venham a sofrer retrocessos - vedação do retrocesso.

O grau de reconhecimento jurídico da progressividade na realizaçáo dos direitos sociais é, portanto, a terceira característica relevante. O princípio da realização progressiva até a máxima efetividade é, conforme vimos, uma decorrência do próprio estágio de juridificação do Estado social.

$\mathrm{Na}$ CF88, ainda que não expressamente, tal princípio se reproduz nos objetivos constitucionais gerais (art. $3^{\circ}$ ), nos princípios da ordem econômica (art. 170), nos objetivos da política urbana (art. 182), nas definiçóes dos direitos à saúde (art. 196) e à educação (art. 205) e no planejamento educacional (art. 214), entre outros. Além disso, sua definição expressa no direito internacional é acoplada à Constituição por determinação do parágrafo $2^{\circ}$ do artigo $5^{0^{2}}$, valendo, no Brasil, a seguinte disposição do Pacto Internacional sobre Direitos Econômicos, Sociais e Culturais (PIDESC) ${ }^{3}$ :

Art. 2o. 1. Cada Estado-parte no presente Pacto compromete-se a adotar medidas, tanto por esforço próprio como pela assistência e cooperação internacionais, principalmente nos planos econômico e técnico, até o máximo de seus recursos disponiveis, que visem assegurar, progressivamente, por todos os meios apropriados, o pleno exercício dos direitos reconhecidos no presente Pacto, incluindo, em particular, a adoçáo de medidas legislativas (BRASIL, 1992, grifos nossos).

A ideia de progressividade merece destaque. No PIDESC, ela não tem o sentido de autorizaçáo para o descumprimento massivo de direitos fundamentais até que seja possível realizá-los; pelo contrário, esse pacto juridifica o sentido de permanente progresso social e econômico, somado ao dever de comprovação de que foram aplicados ao máximo os recursos disponíveis. 
Um princípio constitucional daí decorrente é a proibição do retrocesso, conforme interpretação do Comitê sobre Direitos Econômicos, Sociais e Culturais da Organização das Naçóes Unidas (ONU), órgão criado pelo PIDESC e autorizado a interpretá-lo:

O fato de se estabelecer a realizaçáo ao longo do tempo, ou progressivamente, [...] náo pode ser mal interpretado como destituindo essa obrigação de qualquer conteúdo significativo. [...] [a "progressividade"] dessa forma impóe uma obrigação de atuar o mais rápido e efetivamente possível em direção àquele objetivo. Além disso, todas as medidas de caráter deliberadamente regressivo requerem a mais cuidadosa consideração e devem ser plenamente justificadas em relação à totalidade dos direitos previstos no Pacto e no contexto da completa utilizaçáo do máximo de recursos disponíveis. (ONU, 1991, tradução livre).

Portanto, enquanto a progressividade diz respeito ao objetivo de máxima realização dos direitos sociais, há obrigações imediatas e inadiáveis, como a adoção permanente de medidas, a aplicação do máximo de recursos disponiveis e a não retroatividade. "Esse princípio coloca sob avaliação a priorização das decisões de política pública e implica a análise do uso dos recursos não só nos setores diretamente relacionados com os direitos humanos, mas de toda a Administração Pública” (OSKOZ, 2013, p. 140-141, tradução livre).

Permite também colocar em questão a própria noção de "recursos disponíveis" diante de decisões em matéria de política fiscal e tributária que venham a restringir a destinação orçamentária necessária à realização prioritária dos direitos fundamentais. A aplicação dessa noção à avaliação do grau de realização da dimensão objetiva dos direitos sociais tem como potencial incluir, nas diferentes instâncias de análise e controle, "temas diretamente relacionados às suas condiçóes de implementação, como a política econômica e fiscal, a justiça tributária e o efeito dos incentivos à iniciativa privada na segmentação socioeconômica do acesso aos direitos sociais" (XIMENES, 2014, p. 165).

A ideia de não retroatividade não se confunde com imutabilidade, porque é sempre possível aprimorar o rol de prognósticos e soluções à disposição do gestor no enfrentamento dos problemas sociais diagnosticados em determinados contextos. Seu efeito se dá na elevação ao nível "superconstitucional" (VIEIRA, 1999) do estágio máximo de realização dos direitos sociais especificamente considerados:

O núcleo essencial dos direitos já realizado e efectivado através de medidas legislativas [...] deve considerar-se constitucionalmente garantido sendo inconstitucionais quaisquer medidas estaduais que, sem a criação de outros esquemas alternativos 
ou compensatórios, se traduzam na prática numa "anulação", "revogação" ou "aniquilação" pura a simples desse núcleo essencial (CANOTILHO, 1999, p. 321).

Ou seja, não se incluem na proibição de retrocesso as reformas constitucionais que elevem o nível de proteção ou mudanças em práticas e políticas públicas que, preservando o grau e extensão dos direitos já implementados, venham a ampliar, de forma combinada, a eficiência, eficácia e efetividade das açóes estatais com vistas a promover maiores benefícios e maior cobertura. Precisamente porque é possível aprimorar o arranjo constitucional protetivo, a boa e equilibrada gestão dos recursos públicos não é um fim em si mesmo, mas condição instrumental indispensável de realizaçáo dos fins constitucionais do Estado, entre os quais a máxima eficácia dos direitos fundamentais (TORRES, 2014).

\section{Garantias constitucionais ao financiamento adequado dos direitos sociais: um microssistema estruturante}

Do ponto de vista do financiamento, o constitucionalmente definido é que ele seja proporcionalmente progressivo conforme tanto o nível de riqueza do país quanto a arrecadaçáo estatal. Atravessar a pluralidade de fluxos de correnteza em relação à gestão das receitas e das despesas públicas à luz desse eixo só é possível tendo na CF88 a segura baliza do que pode ou não ser feito. A esse respeito,

Cumpre apenas assinalar o papel do orçamento público como "meio" privilegiado para que se evidencie o controle sobre a realização daqueles fins constitucionais do Estado e sua capacidade de funcionar como instrumento essencial para promover a aplicabilidade dos direitos e liberdades (TORRES, 2014, p. 359).

Os mecanismos formais de garantia do custeio constitucionalmente adequado dos direitos fundamentais, contudo, não são isoladamente suficientes para a proteção efetiva deles, quando apartado dos demais instrumentos de política fiscal, tributária, orçamentária e de controle do gasto público. Isso porque, à EC95, somam-se diversas estratégias históricas de esvaziamento semântico das vinculaçóes orçamentárias, por exemplo, a sua postergação em recorrentes decretos de programação financeira que lhe contingenciam a execução orçamentária, a perenização da desvinculação de receitas da União desde 1994 até $2023^{4}$ e o manejo abusivo das renúncias fiscais, em descumprimento ao art. 14 da Lei de Responsabilidade Fiscal (LRF), que determina que sejam estimado o impacto orçamentário-financeiro e indicadas as medidas tributárias de compensação. 
Diferentemente do que usualmente se concebe, não tratamos aqui apenas de regras isoladas na CF88 a fixar piso de custeio em favor dos direitos à saúde (artigo 198) e à educação (artigo 212) ou ainda acerca do orçamento da seguridade social (artigo $165, \$ 5^{\circ}$, III). Na verdade, há uma série de dispositivos que se reforçam reciprocamente em prol da primazia fiscal dos direitos fundamentais voltados à realização dos objetivos constitucionais. Tais normas formam um conjunto integrado e sistêmico de tutela do financiamento suficiente e progressivo dos direitos fundamentais que opera como verdadeiro eixo dirigente e finalístico dos orçamentos públicos no país, forte o bastante para justificar a criaçáo de tributos com destinação específica à seguridade social contribuiçôes sociais (CF88, art. 149 e 195) - e estabelecer uma exceção à regra geral de não vinculação de impostos (art. 167, IV), em favor do direito à educação (art. 212).

A CF88, assim, protege juridicamente sociedade e cidadáos detentores de direitos subjetivos públicos à saúde, à educação e a todas as prerrogativas relativas à preservaçáo da vida digna, por um microssistema de tutela do custeio suficiente e progressivo dos direitos fundamentais (PINTO, 2016b). É evidente, nesse sentido, a correlação de proporcionalidade entre o fluxo da receita tributária e as despesas sociais específicas como um verdadeiro pacto fundante que fixa a equação sobre quais meios de que o Estado dispóe para atingir quais fins almejados pela sociedade.

Diante de tais premissas é que compreendemos o referido microssistema como uma verdadeira estrutura de contenção do retrocesso e de proteção da estabilidade jurídica e da progressividade fiscal do financiamento dos direitos fundamentais, para que seja alcançada a finalidade da sua máxima e progressiva eficácia, já comentada.

Algumas disposiçóes constitucionais evidenciam essa característica na CF88:

- há uma sistemática própria ao Orçamento da Seguridade Social, voltado a assegurar os princípios da universalidade da cobertura e da irredutibilidade dos benefícios referidos aos direitos à saúde, à previdência e à assistência social (art.165, $\$ 5^{\circ}$, III; art. 194, parágrafo único, I e IV);

- $\quad$ organização da política pública em nível constitucional, a exemplo do SUS (art. 200) e do Fundo de Manutenção e Desenvolvimento da Educação Básica e de Valorização dos Profissionais da Educação (Fundeb) (art. 211 e ADCT, art. 60);

- $\quad$ impossibilidade de destinação a outra finalidade, ainda que em outro exercício fiscal, e de contingenciamento de despesas obrigatórias ${ }^{5}$ (LRF, art. $8^{\circ}$, parágrafo único; e art. $9^{\circ}, \$ 2^{\circ}$, respectivamente). 
Fato é, portanto, que o rol de garantias fundamentais de financiamento dos direitos sociais contempla não só os deveres de aplicação mínima em saúde e educação, ou ainda as vinculaçóes de receita, mas também integra ao microssistema o regime de competências federativas, responsabilidades e sançóes, com possíveis implicaçóes que enumeramos:

1. intervenção federal nos estados e no Distrito Federal e de intervenção estadual nos municípios por descumprimento do gasto mínimo em saúde e educação, o que inclui essa regra entre os princípios sensíveis da CF88 (art. 34, VII, "e"; art. 35, III);

2. condicionamento das transferências de recursos provenientes das receitas dos Fundos de Participação dos Municípios (FPM) e dos Estados (FPE) à aplicação mínima de recursos em saúde (CF88, art. 160, parágrafo único, inciso II);

3. vedação de transferências federativas voluntárias em caso de déficit de aplicação quanto aos pisos de custeio em saúde e educação, garantindo-se, entretanto, a manutenção da parte dessas transferências voltadas à saúde, à educação e à assistência social (LRF, art. $25, \$ 1^{\circ}$, IV, “b”, e $\$ 3^{\circ}$ );

4. rejeição das contas anuais dos chefes do Poder Executivo (CF88, art. 49, IX; art. 71, I);

5. responsabilidade pessoal do gestor em caso de déficit de aplicação, desvio, fluxo irregular ou falta de condicionamento dos repasses, entre outras formas de mitigar ou fraudar os recursos destinados à saúde e à educação (CF88, art. 208, $\$ 2^{\circ}$; ADCT, art. 60, XI; e legislação infraconstitucional).

Diante de uma sistemática constitucional e que não deveria ser alcançável ao poder de reforma constitucional regressiva, fica evidente, portanto, que os arremedos via ADCT, como as desvinculações (in)constitucionais e a EC95, têm o objetivo sorrateiro de suplantar a essência da própria Constituição, falseando-lhe a execução pela via do constrangimento fiscal impróprio, inconstitucional e, em grande medida, autoritário.

\section{Emenda (In)Constitucional 95: o "estado de sítio fiscal”}

Retomando os impasses trazidos pelo "Novo Regime Fiscal", questionamos, em especial, o art. 110 inserido no ADCT pela EC95, no qual se afastou por quase duas décadas a relação de proporcionalidade até então existente entre arrecadação e destinação obrigatória aos direitos sociais à educação e à saúde. Dito de 
outro modo, o aludido dispositivo derrogou - a pretexto de solução transitória e excepcional - de 2018 até 2036 as garantias constitucionais de financiamento mínimo da União à Manutenção e Desenvolvimento do Ensino (MDE) e às Ações e Serviços Públicos de Saúde (ASPS).

Aliás, a metodologia do ajuste fiscal da EC95 reside precisamente nessa paulatina e previsível situaçáo de descasamento entre receitas crescentes e despesas primárias estagnadas ao longo de 20 anos. O eventual saldo positivo em tal equação será aparentemente destinado à redução dos encargos da dívida pública.

Contudo, ao invés de realmente instituir um limite global de despesas transparente e universal como devem ser os próprios orçamentos, a EC95 prevê a criaçáo de uma espécie de contingenciamento preventivo de despesa primária (teto fiscal = despesa efetivamente paga em 2016 corrigida pelo Î́ndice de Preços ao Consumidor amplo - IPCA), alheio à estrutura tributária, ao fluxo das renúncias de receitas (PINTO, 2018) e sem se dirigir às despesas financeiras, cujos limites de dívida consolidada e mobiliária ainda aguardam regulamentação (CF88, art. 52, VI; LRF, art. 30) (PINTO et al., 2017).

Quanto às demais medidas saneadoras voltadas a obrigar o cumprimento do teto de despesas, a EC95 repete, em maior ou menor grau, os comandos da LRF, inovando, contudo, na fixação do referido teto vintenário de despesas primárias (incluídas aqui as despesas obrigatórias e excluídas as despesas financeiras), ao invés da previsáo anual da meta de resultado primário orientadora dos contingenciamentos de despesas discricionárias, prática de política econômica adotada há décadas pelos diferentes governos da União.

Repetindo na essência as medidas de controle de despesas com pessoal da LRF (arts. 21 a 23), na EC95, o eventual descumprimento dos limites individualizados do Poder Executivo e dos órgãos dos Poderes Legislativo e Judiciário, além do Ministério Público e da Defensoria Pública, levaria à proibição de aumento, reajuste ou adequação de remuneração de servidores e empregados, criação de cargos, empregos ou funçóes públicas ou qualquer outra medida que isoladamente venha a aumentar despesas (ADCT, art. 109, I a III). Também há repetição no art. 113 do ADCT, incluído pela EC95, do comando dos arts. 14 e 17 da LRF, que tratam da obrigação de estimativa de impacto orçamentário de renúncias de receitas. Diferentemente da LRF, contudo, não há na EC95 obrigação expressa de compensação tributária das receitas não arrecadadas em razáo de renúncias fiscais.

No caso específico das despesas mínimas da União com MDE e ASPS, a EC95 substitui os critérios de cálculo dos patamares mínimos atualmente inscritos no inciso I do $\$ 2^{\circ}$ do art. 198 ( $15 \%$ da receita corrente líquida da União) 
e no caput do art. 212 da CF88 (18\% da receita líquida de impostos da União), que vinculam gasto mínimo obrigatório à evolução de receitas apuradas no respectivo ano fiscal, por um critério de estagnação do patamar mínimo calculado para o exercício de 2017, com mera atualização inflacionária. Faz isso nos seguintes termos:

Art. 110. Na vigência do Novo Regime Fiscal, as aplicaçóes mínimas em açóes e serviços públicos de saúde e em manutenção e desenvolvimento do ensino equivalerão:

I - no exercício de 2017, às aplicaçôes mínimas calculadas nos termos do inciso I do $\$ 2^{\circ}$ do art. 198 e do caput do art. 212, da Constituição Federal; e

II - nos exercícios posteriores, aos valores calculados para as aplicaçóes mínimas do exercício imediatamente anterior, corrigidos na forma estabelecida pelo inciso II do $\$ 1^{\circ}$ do art. 107 deste Ato das Disposiçóes Constitucionais Transitórias (BRASIL, 2018).

No caso da educação, o piso de custeio proporcional à arrecadação estatal é conquista que remonta à Constituição de 1934, cuja existência historicamente tem se configurado como um indicador prático de democracia política no Brasil: desde então, é regra que os regimes autoritários eliminem a vinculação de receitas da União à educação, como ocorreu nas Constituiçôes de 1937 (Estado Novo) e de 1967 (Ditadura Civil-Militar), sendo o mecanismo retomado e, por vezes, ampliado nos processos constitucionais de redemocratização - Constituiçôes de 1946 e 1988, esta antecedida da Emenda Constitucional no 24, de 1983, a Emenda "João Calmon" (MELCHIOR, 1997; PINTO, 2000; OLIVEIRA, 2002).

$\mathrm{Na}$ saúde, o legislador constitucional previu a necessidade de se repartir os recursos da seguridade social, de modo que se permita que as áreas da previdência, assistência e saúde pudessem ser financiadas de maneira equilibrada. Por isso, o texto original da CF88 determinara, no art. 55 do ADCT, que $30 \%$ do orçamento da seguridade social vinculado por força do art. 195 seriam o mínimo destinado à saúde. Tal dispositivo, no entanto, nunca chegou a ser cumprido de fato pela Uniáo. Sob esse critério, pela Uniáo, deveria ter sido aplicado R \$ 217 bilhões em ASPS, ao invés dos R \$ 115 bilhóes estimados para 2018.

Paradoxalmente, a fixação do dever de gasto mínimo em saúde pela Emenda Constitucional 29, de 2000, náo minimizou o problema de financiamento insuficiente, apenas o acentuou ao longo dos anos. A existência de parâmetro específico para a União (mera correção anual pela variação nomi- 
nal do Produto Interno Bruto - PIB), diferindo do regime de piso atrelado ao comportamento da receita de impostos fixado para os entes subnacionais, deu causa a uma trajetória histórica de regressividade proporcional do gasto federal em saúde (PIOLA et al., 2013). Tal tendência de retrocessos relativos foi consolidada nos arts. $2^{\circ}$ e $3^{\circ}$ da Emenda Constitucional 86, de 2015, quadro severamente agravado pelo art. 110 do ADCT, introduzido pela EC95.

Na prática, até 2036, o gasto mínimo em educação e saúde tomará para fins de correção monetária — a base de cálculo fixada nos patamares de $\mathrm{R} \$$ 48,98 bilhóes em MDE e de R \$ 109,1 bilhóes em ASPS, tal como foram aplicados em 2017 (BRASIL, 2018). As normas constitucionais do inciso I do $\$ 2^{\circ}$ do art. 198 (saúde) e do caput do art. 212 (educaçáo) da CF88 seguem vigentes, não foram alteradas ou revogadas expressamente, mas deixam de produzir efeitos jurídicos e perdem eficácia até 2036. Com isso, ao longo do tempo, a tendência é de que a falta de crescimento real em tais pisos de custeio implique percentuais de aplicação anuais, proporcionalmente, muito inferiores aos definidos no texto da CF88. A estagnação em valores reais, portanto, da despesa primária global da União e, sobretudo, dos deveres de gasto mínimo em saúde e educação contida nesse teto será tão mais destacada quanto maior for a expansão da arrecadação, em cenário de retomada da atividade econômica do país, ao longo dos 20 anos nos quais a Emenda vigorará.

Ou seja, mesmo a ideia de "congelamento" de gastos não dá conta de explicar a radicalidade da medida, que terá como efeito real e prático a redução drástica em termos proporcionais e em valores per capita das despesas obrigatórias a serem destinadas à MDE e às ASPS. Rossi e Dweck (2016, p. 2), nesse sentido, demonstram que o piso de educação e saúde na EC95 é, na verdade "um piso deslizante", já que as simulaçóes dos autores demonstram que, mantidos os efeitos da medida, "o mínimo para educação seria de 14,4\% da RLI [Receita Líquida de Impostos] em 2026 e 11,3\% em 2036, e no caso da saúde o mínimo seria de 12\% da RCL [Receita Corrente Líquida] em 2026 e $9,4 \%$ em $2036 \%$.

Isso porque, de 2018 em diante, a União está obrigada a resguardar tão somente o quanto aplicou no ano anterior, corrigido pela inflação. Tecnicamente foi alterada não só a base de cálculo dos pisos, como também os indexadores que anualmente lhes quantificam os montantes devidos. Daí é que decorre a perspectiva de que a mera correção monetária, a partir da base de cálculo fixada inicialmente em 2017, desconstruiu a relação de proporcionalidade entre receitas federais e seu dever de gasto mínimo em saúde e educação.

Ainda que, em termos estritamente jurídicos, a EC95 não proíba a União de aplicar em MDE e ASPS valores superiores aos mínimos calculados conforme o art. 110 do ADCT, nem imponha tetos específicos para os Mi- 
nistérios da Educação ou da Saúde, é contrafactual imaginar qualquer progressividade real de custeio a esses direitos no "Novo Regime Fiscal". De início, qualquer elevação orçamentária em termos reais em educação ou saúde, sem garantia de proporcionalidade com o comportamento da arrecadação, exigiria retirar recursos discricionários de outras áreas do Poder Executivo, alimentando-se a disputa fratricida entre diversas áreas de políticas públicas, tendente a prejudicar todas elas. Alheios a isso, por sua vez, os gastos com pessoal ativo e inativo tendem a crescer vegetativamente e a comprimir a margem fiscal para assunção de quaisquer novas despesas discricionárias, incluídas as demandas voltadas à saúde e à educação. Ajuste fiscal algum se sustenta com a pura e simples discriminação entre despesas primárias e despesas financeiras, maldizendo aquelas independentemente do contraste com as respectivas fontes de custeio livres ou vinculadas, enquanto se esconde deliberadamente a repercussão das despesas financeiras para o equilíbrio global das contas públicas. Tampouco é admissível a mitigaçáo dos pisos da saúde e da educação, em face das exceçôes estritamente discricionárias e aleatórias previstas na própria EC95, por exemplo, o custeio das eleiçóes e a capitalização de empresas estatais com atuação no mercado (CF88, ADCT, art. 107, $\$ 6^{\circ}$, III e IV).

A via do ADCT e sua transitoriedade não podem simplesmente ferir de morte o texto permanente da Constituição, como se lhe fosse possível falsear o próprio desmonte estrutural do Estado social e de seu pacto assimétrico, o que já foi bem definido como uma "crise desconstituinte" (PAIXÃO, 2018) ou, em sentido literário, o "Retrato de Dorian Gray da Constituição brasileira" (PINTO, 2016a).

Sob qualquer dos ângulos de análise até aqui discutidos é que definimos a EC95 como uma espécie de "estado de sítio fiscal" (PINTO; BIASOTO JUNIOR, 2016), versão para o orçamento do Estado social e os DESC do estado de sítio propriamente dito e sua prerrogativa de suspender as garantias constitucionais (CF88, arts. 137 e 138), no caso as garantias de piso de financiamento público a tais direitos no âmbito da União, inscritos na CF88.

Ora, precisamente porque existem outras rotas de ajuste fiscal menos gravosas à efetividade dos direitos fundamentais é que se pode refutar a alegada inevitabilidade da EC95 e controlá-la como inconstitucional, sobretudo no que se refere ao congelamento dos pisos de custeio da saúde e da educação. Diferentemente do estado de sítio, aplicável segundo condições constitucionais estritas como graves comoçóes nacionais, ataques estrangeiros e declaração de guerra, o "estado de sítio fiscal" é a imposição de uma política econômica inconstitucional em detrimento de medidas tributárias, fiscais e orçamentárias que seriam compatíveis à CF88. 
As normas jurídicas brasileiras já ofereciam, ao tempo da promulgação da EC95, instrumentos preciosos de promoção do reequilíbrio das contas públicas, sem que estes implicassem - de qualquer modo - constrangimento para o custeio mínimo dos direitos fundamentais. Esse é o tema do tópico final deste ensaio.

\section{Por uma gestão fiscal e orçamentária aderente à Constituição de 1988: alternativas}

A fixação do teto global para as despesas primárias ao longo de 20 anos e, dentro desse teto, o estabelecimento de que os deveres de gastos mínimos em saúde e educação terão crescimento real zero são soluções fiscais alegadamente excepcionais e transitórias que invertem o sentido de proteção ao financiamento adequado dos direitos fundamentais presente na CF88. Tal roteiro desconstrói o orçamento da seguridade social, já profundamente afetado pela Desvinculação de Receitas da União (DRU), ampliada na Emenda Constitucional 93, que juntamente com a EC95 desvirtuam a natureza jurídica de determinadas espécies tributárias (taxas e contribuiçóes sociais).

A EC95, especificamente, impóe a postergação da eficácia dos direitos fundamentais amparados por vinculação orçamentária, impondo uma espécie de "estado de sítio fiscal" (PINTO; BIASOTO JUNIOR, 2016). Por essa razão, trata-se de medida inconstitucional ${ }^{6}$, conforme analisamos, com impactos potencialmente devastadores sobre as políticas públicas.

Consoante ao que argumentamos, a desconstrução da garantia de progressividade de custeio para os direitos sociais amparados por vinculação orçamentária é o núcleo de sentido da EC95, e não um efeito colateral. Isso porque praticamente todas as demais regras ali concebidas - direta ou indiretamente já eram normas vigentes e aplicadas anualmente, por meio de contingenciamento de despesas discricionárias, controle de despesas de pessoal, entre outras, como meios usuais ao cumprimento da meta de resultado primário, na forma exigida na LRF. As mudanças, de fato, necessárias para reequilibrar as contas públicas e promover o custeio constitucionalmente adequado dos direitos fundamentais não demandariam, a princípio, maior inovação legislativa.

Sem sequer tangenciar os complexos conflitos distributivos no campo das renúncias de receitas, nos incentivos creditícios e cambiais e na falta de limites para as dívidas consolidada e mobiliária da União, e, consequentemente, para o montante orçamentário destinado ao custeio da dívida pública federal, a EC95 preconiza uma solução aparentemente fácil, um "canto das sereias" para a gestão cotidiana das escolhas orçamentárias e para a alegada má qualidade das políticas e dos gastos públicos. 
Adota essa posiçáo, portanto, sem nada alterar dessas estruturas de privilégios e da má aplicação de recursos, que se expressam no orçamento público e em sua execução e controle, tais como, além das já referidas: o regime de parcelas indenizatórias, que, além de abusivas, costumam violar o teto remuneratório do serviço público; os inchaços injustificáveis no quadro de pessoal de determinados órgãos e entidades; as discricionariedades na execução e no exame das contas anuais dos entes políticos (que incentivam rotineiros falseamentos de gasto mínimo e os desvios de recursos para fins nada republicanos) e as frouxidóes interpretativas dos órgãos de controle que ocasionam, não raro, perdas bilionárias de recursos que deveriam ser destinados à saúde e à educação.

Nessa conjuntura é que apresentamos alternativas de redesenho orçamentário-financeiro que sejam coerentes com a CF88. Muitos sáo os exemplos de previsôes jurídicas que permitem a busca, até mesmo judicial, da alocaçáo constitucionalmente adequada dos recursos públicos em prol de uma responsabilidade fiscal aderente aos direitos fundamentais; dos quais destacamos:

- a proibiçáo de despesas com publicidade institucional e shows artísticos nos casos em que o ente político não tem quitada a folha de salários em dia e/ou está inadimplente com os pisos constitucionais em saúde e educação (Lei no 9.504/1997, arts. 73, VI, e 75);

- a execução da dívida ativa dos diferentes entes governamentais, evitando-se a prescrição delas, por todos os meios lícitos, inclusive o protesto extrajudicial (Lei $\mathrm{n}^{\circ}$ 8.429/1992, art. 10, X; Lei no 9.492/1997, art. 10);

- o controle sobre as renúncias de receitas sem lastro na correspondente e indispensável medida compensatória, sobretudo as que são concedidas por prazo indeterminado, diante do seu impacto desarrazoado (LRF, art. 14 , caput e $\$ 2^{\circ}$; Lei ${ }^{\circ} 8.666 / 1993$, art. $57, \$ 3^{\circ}$ ) e que acaba por perpetuar ilegal e inconstitucionalmente privilégio fiscal no orçamento público.

Tendo em vista esse contexto de possibilidade de ação com base na legislação já vigente, cumpre ressaltar, contudo, que melhor e mais íntegro controle sobre o uso dos recursos públicos é ponto de partida, mas não basta, porque as causas estruturais de desequilíbrio fiscal seguem alheias ao debate público provocado pela EC95. A vinda de um "Novo Regime Fiscal" adia e, de certa forma, mantém oculta a real demanda pela reforma tributária, única capaz de enfrentar a injusta regressividade e a irracionalidade federativa do nosso modelo arrecadatório.

Ao inverter o sentido do orçamento público, comprimindo os gastos primários para descomprimir as despesas financeiras, a EC95 também oculta a imperativa necessidade de fixação das balizas para a gestáo da dívida pública fe- 
deral, com o estabelecimento de limites máximos de endividamento (portanto, de comprometimento orçamentário com o custo da dívida), além de deveres de transparência e motivação para ele.

É, portanto, na reforma tributária e no controle do endividamento que residem o núcleo dos maiores conflitos distributivos incidentes sobre o orçamento público, justamente aqueles campos que ficam à margem da política de ajuste fiscal estruturada na EC95. A esses pontos podemos somar o necessário debate sobre as distorçóes no sistema previdenciário geral e dos servidores públicos, inclusive militares.

A exemplificação e breve análise aqui empreendida, portanto, apontam rotas alternativas de ajuste fiscal que seriam compatíveis com o projeto da CF88, além de iniciativas possíveis de aprimoramento do ciclo orçamentário relativo às políticas públicas, alternativas que vão pela contramão da falaciosa linha argumentativa hoje disseminada, que prega uma incompatibilidade endógena entre responsabilidade fiscal e custeio progressivo de direitos sociais, como se só fosse possível restabelecer aquela tolhendo o alcance destes.

Segundo os ideólogos dessa posição, "a Constituição não cabe no PIB" (ISTOÉ, 2016) e a destinação obrigatória de recursos para a seguridade social, a saúde e a educação seria o pecado original da Constituiçấo brasileira, razão de todos os males econômicos. Isso, a ponto de o programa "Uma Ponte para o Futuro", produzido pelo PMDB do entáo vice-presidente Michel Temer durante o percurso para se fazer substituir abruptamente à presidenta Dilma Rousseff (PT) em 2016, ter anunciado (e cumprido):

\begin{abstract}
Se quisermos atingir o equilíbrio das contas públicas, sem aumento de impostos, não há outra saída a não ser devolver ao orçamento anual a sua autonomia. [...] Para isso é necessário em primeiro lugar acabar com as vinculaçóes constitucionais estabelecidas, como no caso dos gastos com saúde e com educação (PMDB; FUNDAÇÃO ULYSSES GUIMARÃES, 2015, p. 9).
\end{abstract}

Quem vende soluçóes aparentemente novas e drásticas para problemas antigos de natureza política, na verdade, vende ilusóes, algumas delas francamente inconstitucionais. Medidas como a EC95, inspiradas no "Uma Ponte para o Futuro", visam retirar da agenda o debate de medidas estruturantes como a reforma tributária, utilizando-se, para isso, do eufemismo "sem aumento de impostos". Caberia nomear o sujeito oculto nesse mandamento: sem aumento de impostos para quem?

Tão controversa é a rota de ajuste fiscal seletivamente focada apenas no controle das despesas primárias federais que, ao longo de 2017 e de 2018, a 
sociedade viu inúmeras iniciativas francamente contrárias ao seu propalado horizonte de austeridade. A realidade vivida pela populaçáo brasileira comprovou se tratar de mera falácia argumentativa contra a aventada necessidade de um ajuste fiscal amplo, mas nada isonômico e impessoal. Para que ninguém duvide do mau uso da discricionariedade alocativa advinda da EC95, vale lembrar, por exemplo, a majoração de renúncias fiscais federais, que somaram R \$ 354,7 bilhōes em 2017, muito acima de todo o gasto da União em saúde, educação e assistência social naquele ano ( $\mathrm{R}$ \$305,8 bilhóes).

Além disso, destaque-se a reiteração de programas de refinanciamento de débitos tributários para sonegadores contumazes, a alocação superior a $\mathrm{R}$ \$ 2,6 bilhóes para os fundos eleitoral e partidário, o abrandamento das exigências legais para adesão à repactuação de dívidas dos entes subnacionais, entre outras medidas de explícito fisiologismo fiscal, danosas ao financiamento do Estado. No ano em que a Constituição Cidadá completa três décadas de vigência, o maior teste normativo acerca da sua resiliência vem exatamente da derrogação da regra nuclear de proporcionalidade dos gastos primários em relação ao comportamento da receita que, até 2017 , marcava o regime jurídico dos pisos de custeio da saúde e educação e, por conseguinte, determinava a primazia do custeio dos direitos sociais no ciclo orçamentário.

De todos os horizontes que se abrem para a sobrevida do pacto civilizatório assimétrico de 1988, esse é, sem dúvida, o maior e mais desafiador, porque não basta a esperança - há de haver uma ação cívica e plural capaz de mobilizar a agenda das finanças públicas para o seu fim último de realização dos direitos fundamentais. Afinal, como bem dizia Paulo Freire (1992, p. 5), "enquanto necessidade ontológica a esperança precisa da prática para tornar-se concretude histórica". Uma iniciativa potente e exemplar nesse sentido é a campanha "Direitos Valem Mais, Não aos Cortes Sociais: por uma economia a favor da vida e contra todas as desigualdades", fruto de uma ampla coalizão que pede a revogação da EC95 e o fim das políticas de austeridade econômica ${ }^{7}$.

$\mathrm{Na}$ essência, é preciso consertar o mastro da constitucionalidade e recolocá-lo no lugar central da primazia de custeio aos direitos fundamentais no orçamento público, que se ancora na progressividade e na proporcionalidade de sua implementação frente ao montante das receitas estatais. Eis o "Espírito de 1988" que precisa ser resgatado e defendido na celebração das suas três décadas de vigência e sobrevivência.

\section{Notas}

1. Neste trabalho, usamos também a expressão sintética "direitos sociais" como sinônimo de "direitos econômicos, sociais e culturais". 
2. O Supremo Tribunal Federal (STF) definiu que tratados internacionais como o PIDESC ocupam "lugar específico no ordenamento jurídico, estando abaixo da Constituição, porém acima da legislação interna" (RE 466.343, julgamento em 3 de dezembro de 2008).

3. Promulgado pelo Decreto no 591/1992. No mesmo sentido, dispóe o art. $1^{\circ}$ do Protocolo Adicional à Convençáo Americana sobre Direitos Humanos, promulgado pelo Decreto 3.321/1999.

4. A Emenda Constitucional no 93, de 2016, prorroga a desvinculação de receitas da União e estabelece a desvinculação de receitas dos estados, Distrito Federal e municípios, ambas com alíquota de 30\%; mantém ainda excluídos da incidência das desvinculaçôes os recursos vinculados à manutenção e ao desenvolvimento do ensino, conforme a Emenda Constitucional 59, de 2009.

5. Hipótese confirmada pelo STF no julgamento cautelar da Arguição de Descumprimento de Preceito Fundamental (ADPF) 347, ao tratar do contingenciamento do Fundo Penitenciário Nacional.

6. Existem várias Açôes Diretas de Inconstitucionalidade (ADI) contra a EC95 com o STF, a que aborda especificamente a sua repercussão sobre os pisos de custeio da saúde e da educação é a ADI 5658.

7. Para mais informaçóes sobre essa iniciativa, consultar <http://direitosvalemmais.org.br/>. Acesso em: 05 jun. 2018.

\section{Referências}

BRASIL. Constituição da República Federativa do Brasil. Brasil, 1988. Disponível em: <http://www.planalto.gov.br/ccivil 03/Constituicao/Constituicao.htm>. Acesso em: 5 jun. 2018.

Decreto $n^{\circ}$ 591, de 6 de julho de 1992. Atos Internacionais. Pacto Internacional sobre Direitos Econômicos, Sociais e Culturais. Brasil, 1992. Disponível em: <http:// www.planalto.gov.br/ccivil 03/decreto/1990-1994/d0591.htm>. Acesso em: 5 jun. 2018.

Tesouro Nacional. Relatório resumido da execução orçamentária do governo federal e outros demonstrativos. Brasília: Secretaria do Tesouro Nacional, 2018. Disponível em: <http://www.tesouro.fazenda.gov.br/documents/10180/352657/RREOdez2017\%20 REPUBL.pdf>. Acesso em: 13 maio 2018.

CANOtilho, J.J.G. Direito Constitucional e Teoria da Constituição. Coimbra: Almedina, 1999.

CURY, C.R.J. A constituição de Weimar: Um capítulo para a educação. Educação \& Sociedade, Campinas, v. 19, n. 63, p. 83-104, 1998. http://dx.doi.org/10.1590/S0101$\underline{73301998000200006}$

DUARTE, C.S. Direito público subjetivo e políticas educacionais. São Paulo em Perspectiva, Sáo Paulo, v. 18, n. 2, p. 113-118, 2004. http://dx.doi.org/10.1590/S0102$\underline{88392004000200012}$ 
ELSTER, J. Ulisses Liberto: estudos sobre racionalidade, pré-compromisso e restriçóes. São Paulo: Editora UNESP, 2009.

ESPING-ANDERSEN, G. As três economias políticas do Welfare State. Lua Nova: Revista de Cultura e Politica, n. 24, p. 85-116, 1991. http://dx.doi.org/10.1590/S0102$\underline{64451991000200006}$

FERRAJOLI, L. Los fundamentos de los derechos fundamentales. Madri: Trotta, 2001.

FREIRE, P. Pedagogia da Esperança. Rio de Janeiro: Paz e Terra, 1992.

GOTTI, A. Direitos Sociais: fundamentos, regime jurídico, implementação e aferição de resultados. São Paulo: Saraiva, 2012.

HABERMAS, J. Teoria do Agir Comunicativo. São Paulo: Martins Fontes, 2012. v. 2.

HOMERO. Odisséia. São Paulo: eBooksBrasil, 2009. Disponível em: <http://www. ebooksbrasil.org/eLibris/odisseiap.html>. Acesso em: 8 jun. 2018.

ISTOÉ DINHEIRO. A visão futurista de Meirelles. Istoé, 27 maio 2016. Disponível em: $<$ https://www.istoedinheiro.com.br/noticias/economia/20160527/visao-futuristameirelles/377393 >. Acesso em: $1^{\circ}$ maio 2018.

LOACH, K. O Espirito de 45. Reino Unido: Midas Filmes, 2013.

MELCHIOR, J.C. de A. Mudanças no financiamento da educação no Brasil. São Paulo: Autores Associados, 1997.

NOVAIS, J.R. Direitos sociais: teoria jurídica dos direitos sociais enquanto direitos fundamentais. Coimbra: Coimbra, 2010.

OLIVEIRA, R.P. O financiamento da educação. In: OLIVEIRA, R.P.; ADRIÃO, T. (Orgs.). Gestâo, financiamento e direito à educação. Análise da LDB e Constituição Federal. São Paulo: Xamã, 2002.

ORGANIZAÇÃO DAS NAÇÓES UNIDAS (ONU). Comitê de Direitos Econômicos, Sociais e Culturais (CDESC). General Comment n. 3: The nature of States parties obligations (Art. 2, par. 1). Genebra:ONU, 1991. Disponívelem: $<$ https://tbinternet.ohchr.org/ layouts/treatybodyexternal/ Download.aspx?symbolno=INT\%2fCESCR\%2fGEC\%2f4758\&Lang=en $>$. Acesso em: 13 abr. 2018.

OSKOZ, J. Crisis y Recortes en Derechos Humanos: la defensa de los derechos humanos em tempos de crisis. Madri: Catarata, 2013.

PAIXÃO, C. 30 anos: crise e futuro da Constituição de 1988. Jota, Brasília, 3 maio 2018. Disponível em: <https://www.jota.info/opiniao-e-analise/artigos/30-anos-crise-e-futuroda-constituicao-de-1988-03052018>. Acesso em: 6 maio 2018.

PARTIDO DO MOVIMENTO DEMOCRÁTICO BRASILEIRO (PMDB); FUNDAÇÃO ULYSSES GUIMARÁES. Uma Ponte para o Futuro. Brasília: PMDB, 29 out. 2015. Disponível em: <https://www.fundacaoulysses.org.br/wpcontent/uploads/2016/11/UMA-PONTE-PARA-O-FUTURO.pdf $>$. Acesso em: 17 jun. 2018. 
PIOLA, S.F.; PAIVA, A.B.; SÁ, E.B.; SERVO, L.M.S. Financiamento Público da Saúde: Uma História à Procura de Rumo. Brasília: IPEA, 2013.

PINTO, E.G. ADCT é o “retrato de Dorian Gray" da Constituição de 1988. Consultor Jurídico, São Paulo, 27 set. 2016a. Disponível em: <https://www.conjur. com.br/2016-set-27/adct-retrato-dorian-gray-constituicao-1988>. Acesso em: 5 mar. 2018.

. Da saúde ao sistema prisional, vivemos um Estado de Coisas Inconstitucional. Consultor Jurídico, São Paulo, 31 jan. 2017. Disponível em: <https://www.conjur.com. br/2017-jan-31/contas-vista-saude-aos-presidios-temos-estado-coisas-inconstitucional>. Acesso em: 9 jul. 2018.

. Gasto tributário (não) tem limite de prazo, nem teto fiscal? Consultor Jurídico, São Paulo, 30 jan. 2018. Disponível em: <https://www.conjur.com.br/2018-jan-30/gastotributario-nao-limite-prazo-nem-teto-fiscal >. Acesso em: 2 fev. 2018.

. Um microssistema de tutela do custeio dos direitos sociais nos protege. Consultor Jurídico, São Paulo, 8 nov. 2016b. Disponível em: <https://www.conjur.com.br/2016nov-08/contas-vista-microssistema-tutela-custeio-direitos-sociais-protege $>$. Acesso em: 7 jun. 2018.

PINTO, E.G.; AFONSO, J.R.; PORTO, L.K. É inconstitucional a omissão em limitar a dívida pública federal. Consultor Jurídico, São Paulo, 5 dez. 2017. Disponível em: <https:// www.conjur.com.br/2017-dez-05/contas-vista-inconstitucional-omissao-limitar-dividapublica-federal >. Acesso em: 5 mar. 2018.

PINTO, E.G.; BIASOTO JUNIOR, G. Suspender ou adiar custeio de direitos fundamentais nem deveria ser cogitado. Consultor Jurídico, Sáo Paulo, 3 jul. 2016. Disponível em: <https://www.conjur.com.br/2016-jul-03/adiar-custeio-direitosfundamentaisnem-deveria-cogitado $>$. Acesso em: 7 jun. 2018.

PINTO, J.M.R. Os recursos para a educação no Brasil no contexto das finanças públicas. Brasília: Plano, 2000.

ROSSI, P.; DWECK, E. Impactos do novo regime fiscal na saúde e educação. Cadernos de Saúde Pública, Rio de Janeiro, v. 32, n. 12, 2016. Disponível em: < http:// www.scielo.br/scielo.php?script=sci $\operatorname{arttext} \& \mathrm{pid}=S 0102-311 \mathrm{X} 2016001200501 \&$

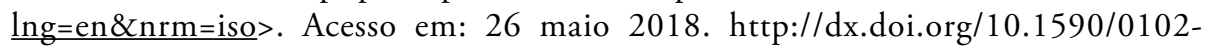
$311 \times 00194316$

SOTELO, I. El Estado social: antecedentes, origen, desarrollo y declive. Madri: Trotta, 2010.

SUNSTEIN, C. Constitutionalism and secession. University of Chicago Law Review, Chicago, v. 58, n. 2, p. 633-670, 1991.

TORRES, H. Direito constitucional financeiro. São Paulo: RT, 2014.

VIEIRA, O.V. A constituição e sua reserva de justiça: um ensaio sobre os limites materiais ao poder de reforma. São Paulo: Malheiros, 1999. 
- Do Compromisso Maximizador ao Constitucionalismo Resiliente. In: VIEIRA, O.V.; DIMOULIS, D.; LUNARDI, S.R.G.; RAMOS, L.O.; NASSAR, P.A.; GLEZER, R.E. (Org.). Resiliência constitucional: compromisso maximizador, consensualismo político e desenvolvimento gradual. Sáo Paulo: Direito GV, 2013. p. $18-24$.

XIMENES, S.B. Direito à Qualidade na Educação Básica: teoria e crítica. São Paulo: Quartier Latin, 2014.

Recebido em 27 de julho de 2018.

Aceito em 10 de outubro de 2018. 